Masi Wali, B.A.,

UOIT, 2012

\author{
An MRP \\ presented to Ryerson University \\ in partial fulfillment of the \\ requirements for the degree of \\ Master of Arts \\ in the Program of \\ Immigration \& Settlement Studies
}

Toronto, Ontario, Canada, 2014

(C) Masi Wali 2014 
I hereby declare that I am the sole author of this Major Research Paper. This is a true copy of the $\mathrm{MRP}$, including any required final revisions, as accepted by my examiners.

I authorize Ryerson University to lend this MRP to other institutions or individuals for the purpose of scholarly research.

I further authorize Ryerson University to reproduce this MRP by photocopying or by other means, in total or in part, at the request of other institutions or individuals for the purpose of scholarly research.

I understand that my MRP may be made electronically available to the public. 


\title{
AFGHAN YOUTH IN TORONTO: BARRIERS TO SOCIAL INCLUSION
}

\author{
By Masi Wali \\ Master of Arts 2014 \\ Immigration and Settlement Studies \\ Ryerson University
}

\begin{abstract}
To identify the barriers to social inclusion that Afghan youth encounter in Toronto, semistructured interviews were conducted with six Afghan youth — three male and three female participants. The data revealed that participants shared (1) experiences of cultural and religious limitations, (2) language barriers, (3) being subjected to discriminatory attitudes, and (4) family responsibilities. Based on theories of Social Exclusion, Social Inclusion, and Social Identity, it was concluded that Afghan youth currently live as marginalized members of Canadian society where their participations in prominent fields such as education, employment, and recreation are limited.
\end{abstract}

Keywords: Afghan youth, social inclusion/exclusion, education, employment, recreation 


\section{Acknowledgements}

I would like to thank Afghan Student's Association York University for their significant contributions to this project. In particular, I acknowledge the professional and supportive guidance of my supervisor, Vappu Tyyskä, and the constructive feedback from my second reader, Harald Bauder. I also thank my family, who constantly encouraged me and provided me with a vision to allow this project to happen. 


\section{Table of Contents}

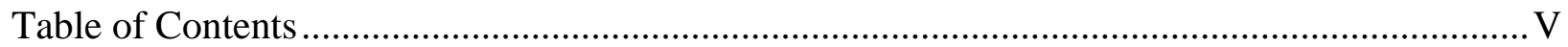

Chapter 1: Introduction \& Theoretical Frameworks ..................................................... 1

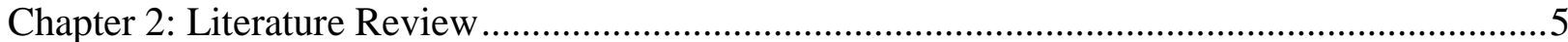

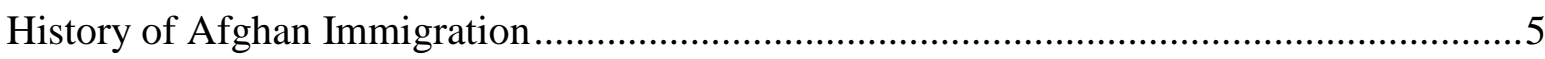

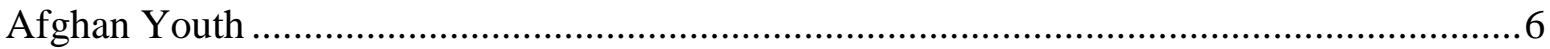

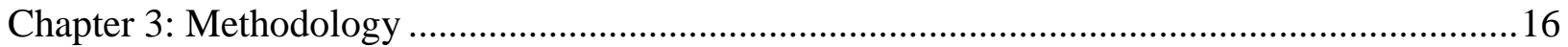

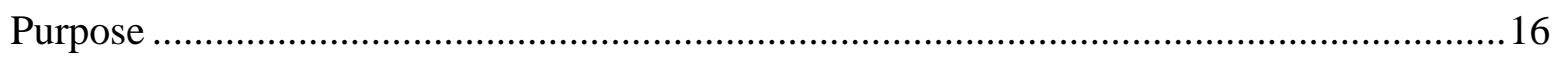

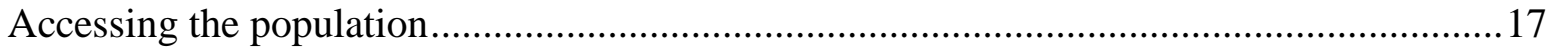

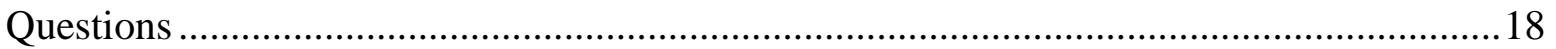

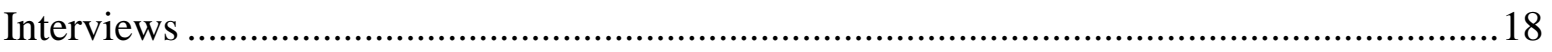

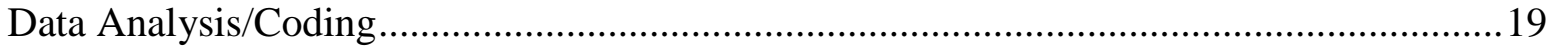

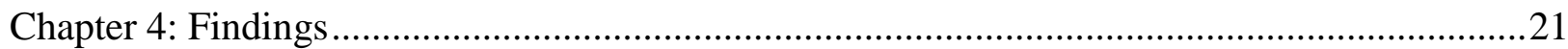

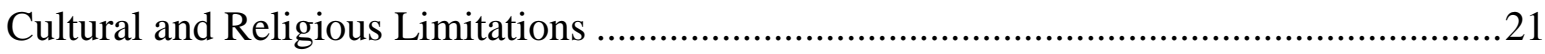

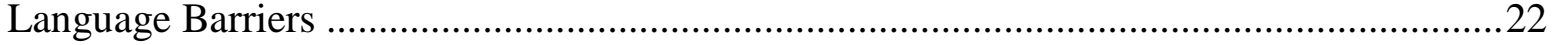

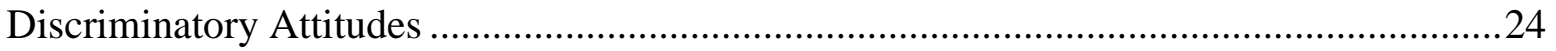

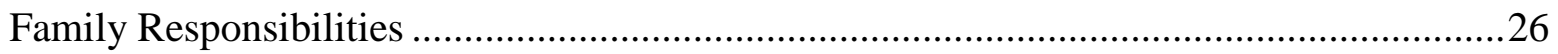

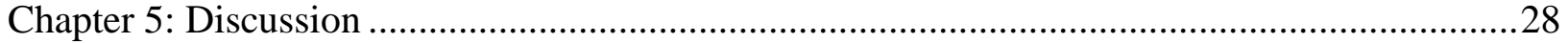

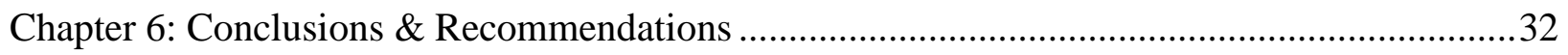

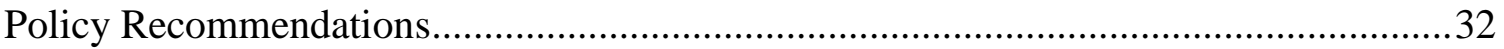

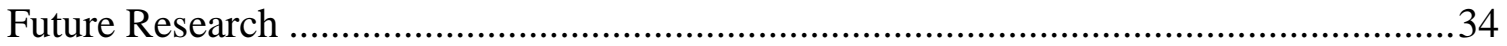

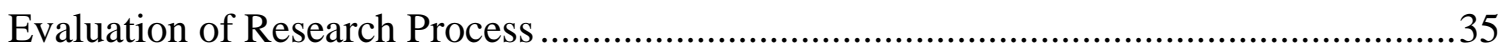

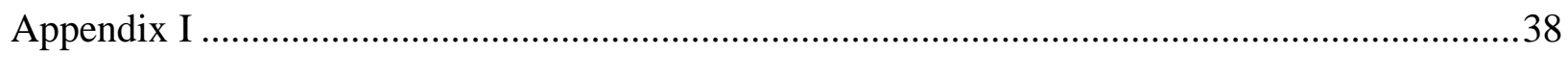

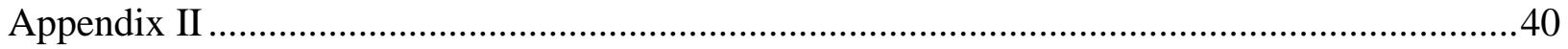

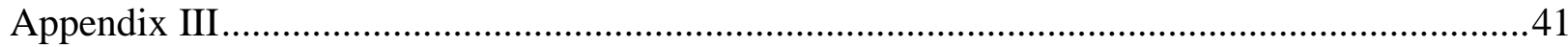

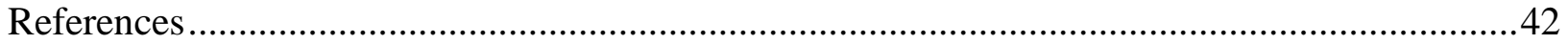




\section{CHAPTER 1: INTRODUCTION \& THEORETICAL FRAMEWORKS}

This chapter outlines the aims and objectives of the research, how the topic was chosen, and the literature that was used to guide it.

The object of this research is to identify barriers to social inclusion that Afghan youth encounter in Toronto. In accordance with Omidvar and Richmond (2005), social inclusion is manifested through the realization of full and equal participation in the economic, social, cultural and political dimensions of life. "It involves the basic notions of belonging, acceptance and recognition" (Omidvar and Richmond, 2005).

Social inclusion is a relatively new concept in social policy. The term was first applied in France during the 1980s to make reference to individuals or groups who were marginalized and remained unaffected by traditional policy interventions and were not covered by security systems of the time; these included single mothers, drug addicts, substance abusers and people with physical and mental disabilities. Since then, both the concept of social inclusion and its antithesis 'social exclusion' have been accepted variably across individual European Union states, particularly the UK and Ireland (European Commission, 2008). Omidvar and Richmond (2003) argue that social inclusion is both a goal and a process requiring commitment from the dominant members of society in bringing forward a condition or state of inclusion.

Social inclusion presumes active participation of all members of society regardless of sex, age, gender, ethnicity, religious affiliation, or sexual orientation in matters that affect them both in a social and political context. The antithesis of social inclusion, 'social exclusion' is a multi-dimensional process in which different forms of exclusion come together: lack of (a) participation in political processes, (b) access to labour market, and (c) integration into a common cultural process (Madanipur, 1977). Numerous Canadian studies have explored the risk 
factors that affect the social inclusion of immigrants and refugee groups. A risk factor is anything that undermines a person's ability to cope when faced with adversity and thereby increase social exclusion. O'Reilly (2006), Jackson (1999), Hanney (2002) identified risk factors to include political and economic risk factors. This involves exclusion from the political and economic spheres resulting from a complex and dynamic set of processes and relations that prevent individuals or groups from accessing resources, participating in society or asserting their rights (Stewart, 2006).

The needs of immigrants and refugees vary from the fulfillment of basic needs such as housing, job skills, and employment opportunities to civic participation and social connections. Canadian Immigration Centre (2012) indicates that nearly all newcomers face significant difficulty and constraints finding housing during their first few years. Recent immigrants also have the second highest unemployment rate (12.3\%) in Canada following Aboriginal people at 14.8\% (Statistics Canada, 2006). For civic participation, recent immigrants (those who migrated in Canada in 2001 or later) have been shown to vote less than others (Statistics Canada, 2011). In addition to these, language proficiency is also key element that affects the economic integration of Canada's immigrants (Nazar, 2012).

Proficiency in English or French not only affects the labour market integration and income level of immigrants but also their community involvement. In a seven year old longitudinal study conducted by Derwing and Waugh (2012), on Mandarin and Slavic-language speakers in Montreal, research revealed that current tactics employed in language training fall short in assisting immigrants to develop the "soft skills" required in finding employment and integrating themselves successfully into the labour market. The authors credit lack of language 
proficiency and inadequate access to cultural knowledge as two factors that limit and inhibit opportunities for immigrants to participate in Canadian society.

Young immigrants are particularly vulnerable, due to social exclusion. In examining the vulnerable groups within the GTA, evidence has indicated that poverty is racialized (Child Poverty in Toronto, 2008). The 2000 Low Income Cut off Before-Tax (LICO-BT) rates of child poverty revealed these rates to be about one in five children for East Asian groups; one in four Aboriginal, South Asian, Caribbean, South and Central American groups; one in three for Arab and West Asian groups, and one in two for children of African groups (Child Poverty in the GTA, 2008). Maund (2009) indicates that children in families who have moved to Canada in the past five years have experienced the highest poverty rates with one in every two recent immigrant children living in poverty.

The racialization of poverty and the slow economic integration of newcomers could be credited to the demographic changes that occurred during the two economic downturns. During this period, the heaviest job losses were in the manufacturing and construction sectors-two industries that employed many of the working poor (Statistics Canada, 2009). Omidvar and Richmond (2005), have criticized Canada's adopted social inclusion policies and their failure to address the rapidly increasing group of immigrants who are excluded from the Canadian economic sphere.

Further, for immigrant children, social exclusion is not limited to economic factors. The failure of public policy frameworks (e.g. The National Children's Agenda) to include children with disabilities is a major social exclusion. For undocumented immigrants, their child who may be denied the right to schooling and access to health care, is indicative of social exclusion 
(Omidvar and Richmond, 2003). Social exclusion is also experienced in the school system through ethnic discrimination by teachers and peers that negatively affect immigrant children's social competence (Martinez, Rummens, Moreau, Choi, Beiser, Armstrong 2012). The latter study also revealed that one in five immigrant children reported feelings of isolation and alienation.

Thus, for immigrants and particularly immigrant children and youth, social inclusion rests on the removal of obstacles and barriers that individuals might encounter with respect to labour market integration, affordable housing, civic participation, and accessibility to social services. A cycle of disadvantages (e.g. poor neighbourhoods, lack of social network, unemployment, and discrimination) prevent individuals from being included in society. 


\section{CHAPTER 2: LITERATURE REVIEW}

\section{History of Afghan Immigration}

It is important to understand the social, physical, and mental health of Afghans prior to their migration in order to have a comprehensive view of their settlement in Toronto. Afghanistan has faced a series of wars and political conflicts over the past 23 years. This includes the Soviet war (1979-1989), civil war of 1989-1992 during which Najibullah's government collapsed, civil war of 1992-2001 (Taliban period) and the war in Afghanistan (2001-present) with ISAF/NATO involvement. During this two decade war period, Afghan families have lived through trauma and suffering, experienced the loss of immediate family members, loss of property and livelihood.

The crisis has had a significant negative impact on the health and well-being of millions of Afghans. This period of conflict has resulted in over 1.5 million deaths including more than 300,000 children (Khan, Khan, Laaser, Chotani, 2003). In accordance to a survey conducted by World Health Organization (2002), 60 percent of Afghan children have lost their primary caregivers and 39 percent have lost their homes over the two decades of war.

Many Afghan families currently living in Afghanistan face extreme poverty and are deprived of basic human needs, including food, safe drinking water, sanitation facilities, health, shelter, and education. Many children are compelled to drop out of school and obtain employment in order to provide an income for the family. An estimated 500,000 children residing in the capital city Kabul occupy jobs such as working on farms, collecting water and firewood, shoe polishing, selling fruits or newspaper and begging on the streets (WHO, 2001). Afghanistan, having one of the worlds' poorest human development indicators has compelled 
many Afghan citizens to leave their homeland in search for better life. Afghans currently represent the largest single group of refugees worldwide with an approximate 6 million displaced Afghans scattered across Europe and North America (Khan et al, 2003). The exact number of Afghans currently residing Canada is not known, but the 2006 Census counted 48, 090 Canadians with ancestry from Afghanistan (Census, 2006).

The Afghan community in Toronto has developed considerably over the last decade with an estimated population of 60,000 residents in the GTA (Exploring the Mental Health Needs of Afghans in Toronto, 2003). However, as the community increases in size with an average of 1,000 new immigrants every year, concerns have been brought to the fore in regards to the integration of Afghan youth in Canadian society. The pre-migration experiences of Afghan youth (i.e. war trauma, poverty) pose as barriers to their social inclusion in mainstream Canadian society.

The profile of refugees more often than not includes those who have minimal formal schooling in their first language; including low literacy in their own language, and low levels of literacy in English. Additionally, they have lived in insecure societies where civil order and services have broken down; many have experienced violence, and may be suffering effects of trauma; and may have spent long periods in refugee camps. The majority of Afghan families fall under one or more of these categories.

\section{Afghan Youth \& Education}

The majority of Afghan newcomers in Toronto are young with over half of the community under the age of 25 (Ornstein, 2006). The challenges encountered by Afghan youth in Canada include prejudice (Khanlou, Koh, and Mill 2008) and extremely high rates of poverty and unemployment 
(Ornstein, 2006). Settlement service providers have indicated depression, isolation and suicide as some of the leading issues faced by Afghan youth (SAFE, 2003).

Nazar (2012) asserts that the majority of Afghan youth migrating to Canada are unable to write or read in any language whether it's the language of their previous country of residence or mother tongue (Dari and Pashto being the main languages). Many Afghan youth have limited educational background prior to their migration due to interruption in their schooling as a result of moving from one country to another or lack of access to proper education while residing in refugee camps.

In accordance to the Organization for Economic Co-operation and Development (OECD), newcomer youth who face difficulty in integrating themselves into the Canadian school system are "at risk" of not having a successful transition into adult life, and hence the labour market. Afghan youth in Toronto fall under this category in accordance to the Toronto District School Board Census (TDSB, 2006), which indicates that Dari and Pashto-speaking students are one of the most 'at risk' - those who are more likely to drop out of high school and less likely to apply to post-secondary education (Brown, 2009). This may be a result of many factors that weaken academic performance or impede attempts at learning. Amir (2009) proposed lack of language proficiency as a key factor that may negatively impact the academic performance of Afghan youth. Language barriers for Afghan youth obstruct their social and academic integration in the school system. Afghan refugees immigrate to Canada from different countries including but not limited to: Pakistan, Iran, and Russia. Therefore, many Afghans learn multiple languages prior to learning English. The difficulty of learning a particular language usually relies on the linguistic proximity of that language to the mother tongue of the individual learning. Dari-the 
common language spoken among the Afghan Diaspora is significantly different from English in structure, script and vocabulary.

Poverty is also a major impediment to positive academic performance, and is widespread in the Afghan community. Ornstein (2006) indicates that the Afghan community ranks second as the most economically disadvantaged ethnic minority group of Toronto. Poverty and economic insecurity clearly have detrimental effects on the youth and their educational experience. The inability to afford basic school supplies, school trips, and specific clothing can lead to negative emotional experiences in school. Bedri (2009) explains that school is a very judgemental place where students who lack economic resources and are different from their peers may develop feelings of marginalization and incompetency. The intensity of such negative feelings could potentially lead to psychological harm. Therefore, economic instability and poverty are major contributing factors to the negative educational experience of Afghan youth.

In addition to language barriers and economic problems, discrimination in school is also a major dilemma for Afghan youth. Soroor \& Popal (2005) in their study indicated that discrimination both within the school settings and outside of school have had a negative impact on the academic integration of Afghan youth. Two-thirds of the participants in their study reported experiencing racism, discrimination or islamophobia in school. Social psychological research over the years has indicated that discrimination is a major risk factor for positive school performance. Personal experiences of discrimination have been correlated with poor mental health, including feelings of anger and depression. Children who are bullied, teased or discriminated upon by their peers at school are more likely to have low self-esteem, and negative academic and socio-emotional outcomes (Wentzel \& Asher, 1996). Muslim parents have also expressed their concern about the discrimination that their children encounter in school settings, 
particularly following 9/11 (Soroor et al, 2005). Hynie, Guruge, and Shakya (2012) further state that discrimination in school in many instances has led to child-parent conflicts where the parents' powerlessness in protecting their children from such discrimination has undermined their authority in the eyes of their children.

An additional factor that significantly impacts the academic performance of children is lack of parental involvement in their child's schooling. Parental involvement and assistance in education provides an opportunity for the child to develop positive attitudes, mental health, social behaviour, school attendance, and most importantly academic performance. However, in Sadat's study (2008), it was revealed that Afghan parents in Toronto are preoccupied with their own settlement problems and societal adjustment. Language barriers, downward socioeconomic and political mobility, credential recognition, unemployment, cultural adjustment, community isolation, prejudice, discrimination, and homesickness are some of these problems (Sadat, 2008). Parental involvement in school is mainly limited due to the language barriers that parents also encounter (Nazar, 2012). Therefore, lack of language proficiency in English is also the rationale provided for lack of parental involvement. Unfamiliarity with language prior to migration and post migration not only poses a barrier for parents in helping children with their academic work but also restrains parent-teacher communication in understanding and assessing the child's academic performance.

\section{Afghan Youth \& Employment}

Several Canadian studies have indicated unemployment as a risk factor that affects social inclusion of immigrants and refugee populations (Salojee 2003, Omidwar \& Richmond 2003, Pedakur 2004, Lochead, 2003). Mwarigha (2002) states that there are three stages of adjustment 
following migration — the initial stage requires language translation and interpretation services; second stage requires access to institutions and programs to facilitate the development of labour market skills and integration; and the third stage includes accessing health services, housing and employment related language training. Mwarigha places heavy importance on the development of labour market skills and employment in both second and third stage of adjustment. Statistics Canada (2003) reveals that 70\% of immigrants struggle to find employment which is the key element of successful integration in Mwarigha's three stages of adjustment.

The Canadian Council on Social Development (CCSD, 1998) has stressed that youth unemployment rate is reaching critical proportions, and that the largest category experiencing problems appears to be immigrant adults and their children. The pre-migration experience of immigrants in their employment field seems to be of no importance to Canadian employers who expect Canadian work experience. CCSD supports this notion by stating that newcomer youth face numerous and greater obstacles in comparison to their Canadian counterparts, due to no Canadian work experience (CCSD, 1998). Other factors contributing to poor workplace success include lack of social networks, language barriers, poor educational background, and family responsibilities (CCSD, 1998).

Unemployment or underemployment are a major concern in the Afghan community. A study conducted by Sabawoon Afghan Family Education (SAFE, 2003) required participants to indicate the main stress factor that affects their life as well as their friends and families. Fifty-two percent of the respondents identified employment and underemployment as their response. As stated earlier, language barriers are a major problem for Afghan youth affecting them in every dimensions of integration. Language is a key element contributing to economic capital, which signifies the quality of one's occupation, productivity and income. Therefore, individuals who 
have language barriers may also have job instability, short working hours, and poor working conditions. Inadequate knowledge of English also results in low wage positions, longer working hours in job positions that are physically challenging.

Afghan immigrants and refugees who arrive as newcomers often face the complexities of occupying poor employment positions and are thus placed in a socio-economic disadvantage in comparison to their Canadian-born counterparts. In Soroor \& Popal's study (2005), three quarters of service providers including child welfare organizations, schools and mental health facilities identified employment and underemployment as the main factor contributing to the deteriorating mental health of Afghan youth in Toronto.

Immigrant families, particularly individuals who are classified as refugees often arrive with limited human and financial capital. Consequently, both parents and children are forced to take up work to financially support their families. However, for many Afghan families, parents are unable to obtain employment or they are underemployed (Amir, 2009). In a study conducted by Kilbridge and Anisef (2001), the average family income for Afghan immigrants was only $\$ 19,600$ - the lowest among all ethnic groups. The authors also found that three quarters of Afghan families live below the poverty line. Due to low wages or no parental income, Afghan youth occupy precarious employment positions in order to support their families (Amir, 2009). In accordance to Statistics Canada (2011), the rate of employment for immigrant youth fell from $49.7 \%$ in 2008 to $45.6 \%$ in 2009 . At the same time, their unemployment rate jumped from $14.0 \%$ to $20.2 \%$

In addition, young people's experienced in seeking employment are also coloured with experiences of racism and discrimination. Many Afghan youth report difficulty obtaining 
employment due to their ethnic and religious background. The issues of racism and discrimination have dramatically heightened for the Afghan community after the events of 9/11 (SAFE, 2003). The media is a significant socializing agent, having significant potential to influence community perceptions. The influence of media has seriously impacted minority groups by subjecting them to exclusionary pressures by implying them as the "other" whose characteristics do not correspond with values and ethos of mainstream Canadian society. Afghan youth in both in Soroor and Popal's (2005) study and in a study conducted by the Sabawoon Afghan Family Education and Counselling Centre (SAFE) credited negative media misrepresentations of Islam and the Muslim community as a factor contributing to the negative perception of Islam for many employers (SAFE, 2003).

\section{Recreational Activities}

The Laidlaw Foundation (2014) recommends recreational activities as a means of allowing adolescents to engage and connect with one another to empower themselves, while becoming involved in the community through these social activities. Recreation is defined as the "physical and artistic experience" of activities that are freely chosen by participants which allow opportunities for progressive skill development and fun (Laidlaw, 2014). However, The Ontario Council of Agencies Serving Immigrants (OCASI, 2005) has criticised the availability and adequacy of recreational programs in Toronto, including the lack of youth involvement in their governance and lack of appropriate recreational models for immigrant youth.

As indicated earlier, experiences of racism and discrimination impede full participation of Afghan youth in all sectors of society, including recreation. Participation in sports in some instances leads to feelings of social exclusion for many young immigrants due to language 
barriers, cultural unfamiliarity with mainstream sports, and discriminatory attitudes from their peers. In order to conform to the country's popular culture of sports and to prevent culture as being a barrier to becoming accepted, many Afghan youth have adopted Christian and AngloSaxon identities to better fit in (Sadat, 2008). However, many studies have indicated that engagement in sport and physical recreation can positively assist with identity formation, social inclusion, and the cultural transition process that immigrant youth encounter (Donnelly \& Coakley, 2002; Omidvar \& Richmond, 2003).

The needs and requirements of Afghan youth are derived from their pre-migration lives which are a reflection of their social values, Islamic culture, religious beliefs, and gender practices which inhibit full participation. In Soroor \& Popal's study (2005), respondents indicated the need for community and recreational services including an Afghan community centre and additional after-school programs and activities. The youth further expressed this need of recreational programs as means of providing a positive outlet for them to keep them out of trouble (Soroor et al, 2005).

Doherty and Taylor (2010) examined the role of sports and physical recreation in the process of "fitting in" to a new country with 40 immigrant ESL high school students from diverse ethnic backgrounds. Their findings indicated that sports and recreation are perceived to be fun, healthy, and helpful, and they contribute to the development of language skills and in providing orientation to the mainstream culture — factors that have been considered as key to successful immigrant settlement. In addition, improved health, learning and academic achievement, development of leadership and communication skills, improvement of self-esteem and confidence, improved quality of life, increased participation in community, and development 
of new skills are also benefits that have been credited to recreational activities (Doherty \& Taylor, 2010).

Nazar (2009) supports the above results by stating that Afghan students who participated in sport clubs and organizations demonstrated improvement in their language communication. Extracurricular activities outside of formal school settings allow and expose students to new people where they could communicate without the pressure that usually exists in formal settings (Nazar et al, 2009). Culturally adopted extracurricular activities for Afghans would a key factor that has potential to improve academic performance. Recreational activities will assist youth in their adjustment while keeping them busy with positive activities. Therefore, there is an urgent need for these services which should be accessible and affordable to all Afghan youth. For families who are facing financial difficulties, these programs need to be free of cost to allow for participation.

Currently, there is a lack of literature available on the migration and settlement experience of Afghan youth in Toronto or the Afghan community in general. Many existing studies were either empirically weak or out-dated. The few studies available fall short of demonstrating the current immigration patterns of Afghans in Toronto and their settlement needs. As a result, the literature review is derived from studies that are over a decade old which leaves a degree of uncertainty about the accuracy and applicability of the information gathered.

As part of filling this gap, the object of this paper is to identify the barriers to social inclusion that Afghan youth face in Toronto as a result of their pre-migration experience and post migration settlement experiences. This is the rationale that provides the foundation for the present investigation. 
Adding on to the available data, this project explores and simultaneously teases out information about Afghan youth's sense of belonging and connectedness within the society in which they reside, while collecting information about their values and belief systems. It enquires about the experiences they underwent in secondary level education, but also their experiences after graduation, in seeking employment, and participation in recreation services. 


\section{CHAPTER 3: METHODOLOGY}

This section discusses the purpose of the study and its relevance, the approach taken and justification for so doing. It describes the data collected, the method of data collection, and some of the difficulties encountered during the research process.

\section{Purpose}

The purpose of this study was to identify the barriers to social inclusion that Afghan youth encounter with respect to education, employment and recreational activities. Through a series of questions about experiences with the secondary school system, with obtaining employment, and with accessing recreation services, the data revealed whether or not Afghan youth experienced full and equal participation in the Canadian society.

This project takes a qualitative approach to the study to enable an in-depth exploration and understanding of the issue. Qualitative research is ideal in research that it seeks to explore the perspective, feelings, and experiences of participants. It relies on perceptions and experiences of participants and may test or challenge an existing theory (Hancock, Ockleford, and Windridge, 2009). The central goal of this study was to discover what life is like for Afghan youth in Toronto as they undergo high school education and post-secondary education, pursue the labour market, and access recreation services within their community. The participants shared the experiences and challenges they encountered, and made proposals for improvements. Their responses described the context of life which could be generalized to all the youth Afghan population in Toronto, with the help of further research.

This study was conducted between July $1^{\text {st }}$ and mid-August 2014, immediately following approval of the proposal by the Research Ethics Board of Ryerson University. The main line of 
investigation in this study are the personal accounts and observations of six Afghan male and female youth between the ages of 18-22 and their experience in three named categories of community life (education, employment, recreation).

\section{Accessing the population}

Access to the Afghan youth population in Toronto was facilitated through Afghan Student Association of York University (ASA@York). The Afghan Student Association (ASA) at York University is a non-profit youth-based organization serving Afghan youth in York University and York region. The organization is dedicated to celebrating Afghan culture while connecting and uniting the Afghan population by building bridges between Afghans within the York University community. The President of ASA was contacted through e-mail. The e-mail consisted of a document explaining the purpose of the study. After signing the consent form, the President then forwarded the document to its members (potential participants) of their organization along with the research description and purpose.

Interested participants who met the criteria outlined in the document then contacted the principal researcher by email. The interested participants were scheduled for an interview at a time convenient for them at York University. The interviews were conducted in a private room on campus. Prior to conducting the interview, a consent form was provided to each participant outlining the purpose of the study, the procedures, the benefits of participating in the research, the risks that are associated with the interview, confidentiality agreement, and their rights as a participant. In addition, the participants were provided with the principal investigator's direct email address. 


\section{Interviews}

Interviews are conducted to obtain insight on a particular subject of interest or research. An interview is considered as a useful tool as it provides an opportunity for further research using methodologies such as observation and experience (Jensen \& Jankowski, 1991).

An interview is a purposeful conversation in which one person asks prepared questions (interviewer) and another answers them (respondent) (Frey \& Oishi, 1995).

Interviews can have one of two basic structures: structured (closed interview style) vs. Unstructured (open interview style). This study used a semi-structured interview style. The rationale behind using a semi-structured interview is the fact that it allows the richness of the data to be completely dependent on the interviewer. In a semi-structured interview, the questions may be tailored by the interviewer allowing a more fluid conversation. Most importantly, it allows for a two-way conversation between the interviewer and interviewee (Jensen et al, 1991).

A semi-structured interview is a flexible interview in which the interviewer does not follow a formalized list of questions. Instead, a list of general topics is created, called an interview guide (Doyle, 2012).

\section{Questions}

Participants were first asked to complete a demographic form (See Appendix II). Prior to the interview, participants were informed that the study inquires about their personal opinions and observation, and there are no right or wrong answers. The semi-structured interviews were based on open-ended questions on three specific topics: education, employment and recreation (see Appendix I). All the interviews were conducted in English. 
Open-ended questions were posed, providing participants with the opportunity to answer, explain and clarify as they responded. Each of the questions inquired about a particular aspect under investigation. The participants were provided with probes and prompts during the interview to keep them in focus or further clarify or elaborate on an answer. All questions were presented to the participants in a consistent manner and logical sequences—school, employment, recreation.

\section{Data Analysis / Coding}

Data analysis was an ongoing process from initial contact to the final report (Rodwell, 1998). The data collected through the interviews included audiotapes of participants, and the notes taken by the researchers. A tape-based analysis was used for the data to be later transcribed. Note based analysis on the other hand included notes from the interviews, the debriefing sessions, and summary of the comments from the researcher.

In accordance to Creswell (2003), Lincoln and Guba (1985), there is no strict criteria or guideline that exists for qualitative analysis or display. As a result, the method of thematic analysis was employed for data analysis. Thematic analysis is the most common form of qualitative analysis categorizing strategy for qualitative data. It includes reviewing data, pinpointing and examining the recording patterns (themes) within data, and sorting it into categories relevant to the description of a phenomenon (Boyatzis, 1998). Each interview was recorded, transcribed and coded into thematic categories.

Post the recording of the interviews, all interview transcripts were printed and read several times. A code name was assigned to each participant. Second, using UMASS - a software for qualitative analysis, I processed all interview transcripts. Each unit of data was 
assigned to its own unique code. In the data set, repetitive patterns were identified as the primary goal was to find repetitive patterns of words or phrases documented in the data. In the example below, note how the process code (a word) is used in a small unit of data:
1،I feel like my religion and culture will
${ }^{1}$ Religion
always be something that restricts me from
the freedom that my friends have" 


\section{CHAPTER 4: FINDINGS}

This section will discuss the findings of the research. I will describe the themes that emerged in examining the research question "What barriers to social inclusion do Afghan youth encounter with respect to education, employment and recreation?" Six individual semi-structured interviews were conducted - three male, and three female participants. All participants, one 18 years old, two participants 19 of years age, and three at 22 years of age were adherents to the Muslim religion. All were fluent in English and Dari, and all were fluent in at least one other language. All six participants were born in Afghanistan, and have been residing in Canada for a minimum of five years. All participants are Canadian citizens, and are single. Three participants are university students, and three participants are university graduates. Of the six participants, four were unemployed, and two were employed part time. Of the six participants, none participated in any recreational activities.

In this research project, the youths' perceptions are the most important. The research found that Afghan youth in Toronto experience barriers to social inclusion as they pursue secondary education, seek employment, and access recreation services. In sum, the youth reported cultural limitations, language barriers, discriminatory attitudes, and family responsibilities as the key obstacles to their social inclusion in Canadian society.

\section{Theme 1: Cultural \& Religious Attitudes}

Three of the six participants stated that cultural and religious attitudes posed as barriers to their social inclusion. For example, 19 year old Ansa (all names are pseudonyms) stated that the exposure to western culture and freedom for both sexes led to more parental reinforcement of religion (Islam) and culturally appropriate discipline for her during her early years of settlement 
in Toronto. After a brief pause and deep sigh, she said: "My parents wanted me to work with them in their own ethnic shop" in order to prevent her from working anywhere else and restrained her from seeking independence.

Despite growing up in Canada from a young age, Mary (19 years old) on the other hand also stated that "culture and religion" may always be factor in her life that sets her apart from her peers and restrain her from the social inclusion in the wider society. She further reflected that “my parents don't find value in education" and want her to focus more on her religious studies and house chores.

Norman, 22 years old, also emphasized culture as a barrier to his social inclusion in Canada. Norman stated that "I have two cultures mixed with me" which makes it difficult for him to adapt into society. During initial years of settlement, it was challenging for him to familiarize himself with anything that was outside of his own cultural norm and he felt like an "outsider." Norman hesitantly stated: "Adapting to western music was difficult as I was too attached to my own cultural music." He further added, "I felt like I did not even exist amongst my classmates".

Norman said he was stigmatized as "teacher's pet” in school due to having the eastern mentality of respecting the teacher to a greater level and regarding them as a parent. He said this led to feelings "frustration". He further added that he faced an "identity crisis" and felt trapped between cultures having difficulty relating to one particular one. "I don't think I'll easily belong back and I can't fully belong here as well, there are gaps".

\section{Theme 2: Language Barriers}

Even though language barriers are being reflected upon in this area, they were not limited to current barriers but also previously experienced barriers. Considering all participants were 
enrolled in a university, English was the only language used for the interviews. Language is a key factor that three of the participants placed heavy emphasis on in terms of social exclusion at school and work. Throughout the study, it is made evident that unfamiliarity with the English language may not only pose a barrier for social integration of immigrants but also their economic and political inclusion. Norman stated that he had to focus extensively on his language skills in order to "blend in." Norman further elaborated that unfamiliarity with the language posed particular difficulties for him and "diminished" the active interest he had in school prior to realizing the importance of education.

Omaid, 19 years of age, also highlighted unfamiliarity with English as a major obstacle for his inclusion in school. He stated that language barriers resulted in him "feeling left out" and also made it difficult to make friends. Outside of school, language "inhibited" his fit into a new culture, or "practice of a new way of life". After looking down for a moment, he looked up with a smile and said how people in his surroundings would give him a "weird look" due to his accent, speaking style and inability to understand idioms. He repeatedly said his parents were "of no help" as they also had language barriers and had completely different expectations of school. "My mom tried to speaking to my teacher many times." However, his parents were told they can't focus on one child since there were many students in the class.

When asked about his experience during the early years of settlement as an immigrant in Canada, Aryan, 22 years of age instantly pointed out to the difficulties that rose due to his inability to speak English. Aryan arrived at the age of 9, and started English with learning the alphabet. When asked about the particular experience that stood out in school, he stated that his classmates and peers would teach him "bad words" and make fun of him afterwards. After a moment of silence, he added "I became violent and angry with everyone." 
Aryan had to be transferred to a LEAP (Literacy Enrichment Academic Program) program to enhance his learning experience. A LEAP is program is a language training and support program offered to newcomer youth in selected elementary schools across Canada. However, he said the experience was both "positive and negative." Although the teacher was very supportive, he was surrounded by other students who were also very violent and had a "bad temper" and used "foul" language towards him.

Commenting on his transition from work to life, Aryan added "the struggle has still not come to an end" despite living in Canada for the past 13 years. "At work I still do not understand certain words or phrases used by my coworkers." At work, he still does not understand some terminology used by coworkers which leads to a sense of "exclusion" and "shame".

\section{Theme 3: Discriminatory Attitudes}

Three of the participants attributed discriminatory attitudes as one action or barrier that denies their social participation or inclusion in their given societies. This either included the unfair treatment they received based on their actual ethnic (origins from Afghanistan) or a religious membership. For instance, when inquired about their experience in school, Norman repeatedly mentioned that "people were discriminatory, either because I was a Muslim or because of my accent."

Norman assumed that ethnic or religious stereotyping would be less in cities that are more diverse and culturally concentrated. However, this was not the case for Norman. He stated that he faced more exclusion when he came to Toronto: “...there was a culture of difference flourishing between the whites and non-whites, coming into that gap, and I saw that I belong to one and not the other". He also indicated that due to his unfamiliarity with the music and sports in school, he was called a "fob." 
Aryan also reported discrimination in school settings: "From grade 5 to grade 8, the majority of the white kids would make fun of my accent and the way I used to dress". Aryan also stated the he felt the teachers were more favourable to white students or students who knew how to speak English and had less trouble with their studies. "I felt like an outsider, because there would be no one I can talk to, I felt trapped". After looking down for a moment, he expressed: "I would even have my lunch in the bathroom, so I don't get bullied around by other students".

Mariam, 18 years old, also pointed discrimination in school as a major complication she endured when she first arrived in Canada at the age 5. "I remember the first day of school, the teachers were nice, but the vibe I got from other students was unfriendly". Pausing for a brief moment, she stated "I stay in class during recess and go home for lunch as no one wanted to be friends with me." The geo-political events of 9/11 had also shaped some discriminatory attitudes towards Muslim students. Mariam added: "Go back to Afghanistan, go back to your Taliban" was one statement she received from a few school mates.

When asked about their experience at the workplace, Norman stated: "I continue to have difficulty obtaining government jobs post-graduation, most managers are of white background, and it's seldom that an immigrant can get a job in the government, I am living example”. He further added: "I feel race, culture, ethnicity are elements that give others a reason to put a stop in front of you which impacts how you perform."

Aryan also mentioned that he experienced discrimination at work: "All the staff were of white descent in my first two jobs, and there was a sense of connectedness amongst them with me feeling left out at all times." He also described that favouritism with management being harsher towards certain employees of specific ethnic backgrounds for minor errors and easier on others belonging in the mainstream. He further added that he would not easily be able to book off 
religious holidays such as Eid and had to make multiple requests to his supervisor, sales manager, and general manager before being granted any days off.

\section{Theme 4: Family Responsibilities}

It was evident from the youth responses that family responsibility and family pressures are one of the factors that contributes to social exclusion. The respondents highlighted that they encountered this challenge during their school phase, transition from school to work as well as their accessibility to recreational services. The lack of financial resources within the family as well as other family obligations such as care-giving impacted their daily lives.

One of the respondents, Ansa stated that when "my friends would tell lets go for swimming at Centennial, its free," her response would be "I still can't afford it" implying that she had work obligations or had to take care of her younger siblings while parents were working. She further added, “At 10, I was selling chocolates, at 12 distributing newspapers." She took every job opportunity she came across despite her young age in order to support the family in providing an income.

Omaid stated that the financial burden of his family partially rested on his shoulders as he not only needed to support himself but also the large family. "I couldn't afford not working, there were expenses that I had, and my parents couldn't support." When asked about his access to recreation, Omaid spoke sadly about his experience, "I simply couldn't afford it; I had to make the earnings for the family because I had three younger siblings." He further added that he was not able to afford the time or the money to commute to these recreational facilities.

Similar to Omaid, Mariam also expressed that although she had access to recreational activities, she didn't' have time she was always at home after school trying to babysit her 
younger sibling. "Everything I wanted to do was happening while I would be working or at home with my younger sister." Mary on the other hand had to support her family by joining the family business: "I started working at age 8 in my parents' tailoring store to cut down on labour cost." Mary's 8 a.m. -3 p.m. school and 4-9 p.m. work schedules prevented her from not only recreational activities but also other social life. 


\section{CHAPTER 5: DISCUSSION}

The findings of this qualitative study suggest that Afghan youth in Toronto encounter barriers to social inclusion when they pursue secondary education, employment, and access to recreation services. These barriers include, but are not limited to, poverty (Ornstein, 2006), lack of language proficiency (Amir, 2009), discrimination (Bedri, 2009), and lack of parental involvement (Nazar, 2012). My study connects with these findings from previous research, while also presenting additional elements. The findings in the present research strongly illustrate that the post migration experience of the participants act as barriers to their sense of inclusion in Canada. The participants shared their feelings and described several difficulties they endured post migration that inhibited their social inclusion. They highlighted personal experiences such as religious and cultural barriers, language issues, discrimination, and family responsibilities. What was previously known about the first three, is confirmed by my study. In addition, I also found that family responsibilities are a significant issue, rooted in the economic and social exclusion of Afghan immigrant families. I will discuss all four aspects of inclusion/exclusion below, in more detail.

To begin with, despite arriving to Canada at an early age, majority of the participants highlighted cultural and religious attitudes as a factor that posed as barriers to their social inclusion. Notably, there was a relationship between the gender of the participants and the themes that emerged. For example, more female participants indicated cultural and religious attitudes and family responsibilities as a major barrier to their social inclusion while their male counterparts emphasized language barriers and discrimination as their barrier. This gender element will be taken up again and in more detail below. 
Further, exposure to the western style of living led to strict cultural and religious enforcement for all the youth by their parents. This leads to a sense of struggle for the youth to fit into a new culture, practice a new way of life, and also leads to identity crisis. Connor and Koenig (2012), confirm this issue by providing a context-dependent example of how religion affects an immigrant's structural integration. Reflecting on theories of inter-generational immigrant integration, the authors recognize and define two context-dependent mechanisms through which religion and culture interfere with social integration: (1) as an ethnic symbol leading to exclusion and discrimination, or (2) as a social organization providing access to tangible sources (Connor and Koening, 2012). Findings of the current study tie in with the first perspective that religion or culture is an ethnic symbol that may exclude immigrants from the wider society. This was evident in our study in two distinct ways. Firstly, Afghan youth faced an exclusion based on their parental enforcement of their religion and cultural values which inhibited their full participation in the society. Secondly, Afghan youth encountered discrimination based on the religious symbol they signified themselves as.

As noted, a large segment of the research available on the integration of immigrants in Canada has focused on their economic performance. Studies such as, Picot and Sweetman(2012), Derwing and Erin Waugh (2012) have indicated that official language skills have significant direct and indirect influences on the labour market integration of immigrants and are key to positive economic outcomes. Despite the point system in place which is largely motivated by economic factors, there is growing income gap between immigrants and Canadian born (Census, 2006) and language is considered the backbone of this problem. Therefore, there is a strong assumption that for an immigrant to be socially and economically integrated in the Canadian society, they must relatively proficient in an official language. This is evident in this study as 
participants describe how their language barriers can lead to limited opportunities for them to fully participate in Canadian society. All participants reported feelings of exclusion and discrimination in all spheres of life including school, employment and recreation due to their language difficulties.

Khanlou, Koh, and Mill (2008), argue that in culturally diverse immigrant receiving societies, refugee and immigrant youth can be victims of prejudice and discrimination. Such undesirable experiences could have a negative influence on the youth's self-identity, cultural identity and psychosocial outcomes. Their findings and Tajfel's social identity theory (1979) correspond with the findings of the current study. Tajfel (1979) proposed that groups (e.g. social class) which people belong to are an important source of pride and self-esteem and provide us with a social identity. As a way of increasing our self-image, we attempt to enhance the status the status of the group to which we belong. Such an attempt may also provoke discrimination and prejudice one's views towards other groups. Thus, participants in this study revealed that there are societal factors influencing prejudice such as their social class or poverty levels. Participants also revealed personal experiences of discrimination based on their ethnic or religious affiliation which relates to Tajfel's social identity theory. Furthermore, preservation of cultural identity was either enforced by parents or the youth themselves. However, in many instances, the youth also indicated fear of disclosure and silenced cultural identity due to discrimination.

In accordance to Tyyskä (2003b and 2006), many immigrant youth feel torn between their desire to fit in with the peers and their desire to meet their parents' expectations, and that these experienced are gendered. Throughout the study, it can be seen that the female participants reported much less freedom movement and decision making than their male counterparts. 
Although both genders were under strict financial obligations by their parents, the level of freedom varied. More female participants reported the responsibility of babysitting a younger sibling. Family financial burdens as well as the different role expectations from the participants inhibit the full participation of both genders, but female participants a little more, seen in the emphasis on parental controls on their movements. 


\section{CHAPTER 6: CONCLUSION \& RECOMMENDATIONS}

The objective of this study was to explore the narratives of Afghan youth and the barriers to social inclusion they face in Toronto. The study factored in the personal perspectives of Afghan youth. A decade after Omidvar and Richmond's study (2003), and three years after Quirke's study (2011), many of the same issues appear in the present study, for Afghan youth. The findings in this study are also validated by those found in Khanlou, Koh and Mills study (2008), as well as Soroor and Popal's study (2005) in regards to the discrimination experienced by Afghan youth in school settings, and barriers to employment they encountered due to their religious affiliation and cultural identity. Drawing on Tajfel's social identity theory, it was established that Afghan youth face discrimination and prejudice due to their social class (linked to low income and poverty levels), and their religious affiliation. Using theories of Social Inclusion and Social Exclusion, it was concluded that Afghan youth currently live as marginalized members of Canadian society where their participation in prominent fields such as education, employment and recreation are limited.

\section{Policy Recommendations}

My main recommendation is that social inclusion indicators need to be implemented in all areas including practices in education, employment hiring practices, and accessibility to recreation services. In the field of education, the school systems should mandate to serve all students and create an education system that is sensitive to diversity and allow for equal opportunity. Recruitment of teachers from different ethnic backgrounds, especially those of South Asian countries might allow for proximity and involvement of different ethnic background students. There is also a need to implement more language training programs that will enable 
Afghan newcomers to participate fully in their classes and enhance their proficiency in English. In addition, considering the importance and impact of discrimination on the mental health of Afghan youth, anti-discrimination initiatives in schools need to be heightened and more awareness and education needs to be created in this particular area. Particularly co-op students and placement students should have access to a broader system of networks that goes beyond their immediate surroundings to allow room for growth.

In the employment sector, the government should enforce strict anti-discriminatory hiring practice across all small or large companies or firms to prevent stereotyping and racial discrimination. This includes strict accountability, transparent hiring process, and reporting application outcomes. Together, these measures will reduce if not eliminate discrimination. Employers and regulatory bodies need to adopt a more flexible and individual approach in assessing an applicant's qualifications without assuming that one will not succeed due to lack of Canadian work experience. Employers should also identify potential barriers for newcomers in their organization and address such barriers through initiatives such as organizational change, abolishment or replacement of old practices and policies. An applicant should be given an opportunity to prove their qualification and employers should consider all relevant work experience regardless of the country where it was obtained.

As mentioned earlier, strict gender roles, expectations and cultural and religious factors place varying restrictions for young Afghan women in comparison to young Afghan men. For recreational activities, settlement agencies and the government sector need to establish more culturally appropriate, gender-sensitive initiatives that allow full participation of all ethnic groups and communities without discrimination of any kind. Acknowledging the fact that this study has a small number participants, it is difficult to recommend broader policy initiatives or 
recommendations. However, this also leaves room for future research on the topic of social inclusion for Afghan youth.

\section{Future Research}

Future research in this area should further investigate the varying difficulties that female Afghan youth encounter considering the gendered aspect of social exclusion in the Afghan community. It should explore the mental health needs of young female Afghans since the available data has been a male dominated sample population. Research should focus on how to reduce cultural barriers for Afghan women and initiatives in making transitions easier. It should highlight the impact that financial incentives, scholarships, and feedings programmes have had or could have to enhance female participation in schooling.

Research should also differentiate between Afghan refugee youth and Afghan immigrant youth as these groups may have different experiences. Afghan youth are an extremely heterogeneous group, varying in terms of their pre-migration experience, education background, and pattern of migration. Many have arrived from a third country such as India or Pakistan, therefore combining refugee and immigrant experiences. Research needs to move beyond treating Afghan youth as one homogenous group, and acknowledge their complex backgrounds and identities.

Future research in this area should also focus on operationalizing the concept of social inclusion. This should include the active involvement of Afghan community members, the youth themselves along with mainstream policy planners and makers to accomplish creative and innovative results. It needs to be acknowledged that the population under light is young, bright, enthusiastic, and motivated. Therefore, if this group is fuelled by government initiatives and 
policies that promote their involvement in all sectors of society, many tangible outcomes are to be seen.

\section{Limitations \& Evaluation of the research process}

As a researcher, there were a few difficulties and obstacles encountered during the process of the study which also acted as a limitation. This included limitations in the literature review, methodology, and data analysis.

Studies have indicated that one of the main problems in conducting interviews is that they are time-consuming. Preparing the interview, scheduling it with participants at their own convenient time, and inputting notes for data analysis consumed a lot of time. The initial targeted sample size was ten participants, but due to time constraints and schedule conflict, it had to be downsized to six participants.

The information derived from the interviews produced a lot of data. There was no analysis plan before conducting the interviews and therefore difficulties were encountered during data entry and analysis. As the interviews were being transcribed from the tape recordings, there was an increased awareness of the biases with which this project was approached. In order to gain the data required, probes were provided constantly which encouraged participants to give the responses that the researcher either expected or wanted. For example, when asked about their access to recreational activities, three of the participants said they had difficulty accessing it. To further clarify the answer and allow respondents to elaborate, the leading probe "What sort of difficulties? Was it due to language barriers, financial reasons, proximity or any other obligations?" was provided. These options may have influenced the responses obtained. 
Towards the end, it was recognized that the design of the interviews was actually very helpful for data collection. Allowing each person to describe the problems associated with their own social inclusion/exclusion from their own perspective without being manipulated, provided rich and original content. Holding the interviews at a location both familiar and convenient for all of the participants, York University, removed the concern of travelling and transportation for the participants.

The area being explored by the study and the questions designed to obtain this data were relatively easy for the participants to understand and respond to. The open-ended questions, along with probes and prompts permitted for a wide range of discussion that provided an indepth understanding of every unique and personal issue. As a researcher, I had to be careful with the probes I provided to participants in order to prevent getting too personal or assertive with the information the participants wanted to provide. This was the case mostly with the female participants as they hesitated to answer or reflected in some areas, for reasons which were not revealed despite confidentiality and anonymity being guaranteed. The young women may have also been hesitant to respond due to being interviewed by an Afghan male, and if they were interviewed by a woman, their responses may have been different. Being a male Afghan insider researcher may have influenced and shaped the responses the female participants provided. Afghan females in general are very careful of the way they speak and the terminology they use with another Afghan of the opposite gender due to cultural and religious considerations.

As mentioned earlier, time constraint was a key issue that also impacted data collection and analysis. In order to simplify the manageability of this research project, a small portion of data was collected. Descriptive text along with direct quotes from the participants were used to depict the emerging themes from the interviews. The data collected can be deemed valid and 
reliable, and may be used for future studies that will help ascertain a more complete picture of the lives of Afghan youth in Canada. 


\title{
APPENDIX I
}

\section{Barriers to Social Inclusion that Affect Afghan Youth INTERVIEW BACKGROUND INFORMATION SHEET}

\author{
DO NOT \\ Put your name \\ On this sheet.
}

INSTRUCTIONS: Please fill in this that will provide us with some basic background information about you.

1. What is your age?

2. I'm a (Check one):

[ ] Male

[ ] Female

3. Age of arrival in Canada?

4. How long have you been in Canada?
[ ] 5 to 7 years
[ ] 7 to 10 years
[ ] 10 years +

5. Place of Birth:
[ ] Afghanistan
[ ] Canada
[ ] India
[ ] Pakistan
[ ] other: please indicate
[ ] prefer not to answer

6. Marital Status
[ ] Single
[ ] Married
[ ] Separated
[ ] Widowed 
7. Employment Status

[ ] Employed for wages

[ ] Self-employed

[ ] Out of work for more than 1 year

[ ] Out of work for less than 1 year

[ ] A homemaker

[ ] A student

[ ] Retired

[ ] Unable to work

8. Education

[ ] Never attended school or only attended kindergarten

[ ] Grades 1 through 8(Elementary)

[ ] Grades 9 through 11 (Some high school)

[ ] Grade 12 or GED (High school graduate)

[ ] College 1 year to 3 years (Some college of technical school

[ ] College 4 years (College graduate)

[ ] Graduate School (Advance Degree)

Please turn over this brief information sheet and leave it on the table when you leave. Thanks. 


\section{APPENDIX II}

Table 1 Demographics

Item

Numbers

Total Number of Participants

$\underline{\text { Religious Affiliation }}$

Muslim

$\underline{\text { Gender }}$

Female

3

Male

Age

18 years and over

$\underline{\text { Immigration Status }}$

Permanent residents/ Citizens

$\underline{\text { Marital Status }}$

Single/never married

Language

Fluent in English

Fluent in Dari

Fluent in at least one language other than English or Dari

$\underline{\text { Education }}$

University or college graduates

3

Enrolled in university or college

$\underline{\text { Employment }}$

Currently employed

2

Unemployed 


\title{
Interview Questions
}

\author{
Barriers to Social Inclusion that Affect Afghan Youth \\ Masi Wali, (Master of Arts student) \\ (Department of Immigration \& Settlement Studies - Ryerson University)
}

Information about these interview questions: This gives you an idea what I would like to learn about your experience and the obstacles and barriers you face that socially excludes you. Interviews will be one-to-one and will be open-ended (not just "yes or no" answers). Because of this, the exact wording may change a little. Sometimes I will use other short questions to make sure I understand what you told me or if I need more information when we are talking such as: "So, you are saying that ...?), to get more information ("Please tell me more?"), or to learn what you think or feel about something ("Why do you think that is...?").

1. Please tell me about your early years as an immigrant in Canada.

2. What was is it like going to school? What experiences stand out? Why?

3. What has it been like for you move from school to working life? Can you give me some examples?

4. What is working like for you, in the workplace? Can you give me some examples?

5. Do you participate in any recreational activities? What are they? What is your access to the activities you like to participate in? Can you give me some examples?

6. What have your overall experiences been, in participating in school, work and recreation? What do you think could be done to improve your participation in these areas?

7. Would you like to add anything to what you have already said? 


\section{References}

Afghan Association of Ontario (AAO) (2014). Toronto, Ontario, Canada. Retrieved from: http://www.aaocanada.ca/aao/

Afghan Women's Organization (AWO) (2014). Toronto, Ontario, Canada. Retrieved from http://www.afghanwomen.org/index.php?lan=english

Amir M. N. (2009). An analysis on the status quo of Afghan youth in the Ontario school system. Crossing the Finish Line. Afghan Association of Ontario, Canada.

Children's Aid Society of Toronto. (2008). Greater trouble in Greater Toronto: Child poverty in the GTA. Toronto, ON.

Bedri Z., Chatterjee S., \& Cortez R. (2009). Immigrant and refugee youth issues - a perspective from York University students. High School Credential Assessment Program: Valuing Students from all Backgrounds. Research carried out as part 50 of the OCASI Serving Youth in Newcomer Communities (SYNC).

Boyatzis, R. (1998). Transforming qualitative information: Thematic analysis and code development. Thousand Oaks, CA: Sage.

Brown, R. S. (2006). The TDSB Grade 9 Cohort Study: A Five-Year Analysis 2000-2005. Toronto: Research and Information Services, TDSB.

Brown R.S. (2009). TDSB Research Report. An Examination of TDSB Post-Secondary Patterns 17 Year old Student, 2007. Issued by Organization Development, Research and Information Services.

Children's Aid Society of Toronto. (2008). Greater trouble in Greater Toronto: Child poverty in the GTA. Toronto, ON.

Connor, P. and Koenig, M. (2013), Bridges and Barriers: Religion and Immigrant Occupational Attainment across Integration Contexts. International Migration Review, 47: 3-38.

doi: 10.1111/imre.12012

Creswell, J. W. (2003). Qualitative, quantitative, and mixed methods approach (2nd ed.). Thousand Oaks, CA: Sage

Doherty, A., Taylor, T. (2010). Sports and physical recreation in the settlement of immigrant youth.

Donnelly, P., \& Coakley, J. (2003). The role of recreation in promoting social inclusion. Monograph in the Working Paper Series on Social Inclusion published by the Laidlaw Foundation, Toronto, Ontario 
Empowering Afghan lives (2014). Toronto, Ontario, Canada. Retrieved from http://empoweringafghanlives.com/

Exploring the Mental Health Needs of Afghans in Toronto (2003). Sabawoon Afghan Family Education and Counselling Centre.

Frey, J.H \& S.M.Oishi (1995): How to Conduct Interviews by Telephone and in Person. London: Sage.

Hancock, B., Ockleford, E., Windridge, K. (2009). An Introduction to Qualitative Research. National Institute for Health Research.

Hynie, M. \& Guruge, S. \& Shakya, Y. B.(2013). Family Relationships of Afghan, Karen and Sudanese Refugee Youth. Canadian Ethnic Studies 44(3), 11-28

Jensen, K., \& Jankowski, N. (1991). A Handbook of qualitative methodologies for mass communication research. London; New York: Routledge.

Khan, M., Khan, S., Laaser, U., Chotani, R. (2003). Child Health in Afghanistan: a glimpse of the future of a stricken country. Bielefeld, Germany.

Khanlou, N., Koh, J. G. And Mill, C. (2008). Cultural identity and experiences of prejudice and discrimination of Afghan and Iranian immigrant youth. International Journal of Mental Health and Addiction, 6: 494-513.

Laidlaw Foundation, http://www.laidlawfdn.org/index.cfm7group id=1028 Retrieved August 20, 2014

Lincoln, YS. \& Guba, EG. (1985) Naturalistic Inquiry. Newbury Park, CA: Sage Publications.

Maund, J. (2009). 2009 Report Card on Child and Family Poverty in Ontario-From Promise to Reality-Recession Proofing Ontario Families.

Mwarigha, M.S. 2002. Towards a framework for local responsibility. Taking action to end the current limbo in immigrant settlement- Toronto: Toronto: Maytree Foundation.

Nazar, Khesraw E. (2012). Opportunities and challenges: Afghan youth learning English. Toronto, Ontario. Ryerson University.

Newman, J. (2005). Protection through Participation: Young people affected by forced migration and political crisis. RSC Working Paper No. 20. Oxford, England: University of Oxford, Refugee Studies Centre.

OCASI. (2005). Inclusive Recreational Model for Immigrant and Refugee Youth.

Omidvar, R., Richmond, T. (2005). Immigrant settlement and Social Inclusion in Canada. CERIS No. 16 
Ornstein, M. (2006). Ethno-racial groups in Toronto, 1971-2001: a demographic and socioeconomic profile. Toronto: Institute for Social Research.

Oxman-Martinez, J., Rummens, J.A., Moreau, J., Choi, Y.R., Beiser, M., Ogilvie, L., \& Armstrong, R. (2012). Perceived Ethnic Discrimination and Social Exclusion: Newcomer Immigrant Children in Canada. American Journal of Orthopsychiatry. 82 (3), 376-388.

Pradhan, R. 2006. Understanding Social Exclusion and Social Inclusion in the Nepalese Context: some Preliminary

Sadat, H. (2004). Hyphenating Afghahniyat (Afghan-ness) in the Afghan Diaspora. Journal of Muslim Minority Affairs, Vol. 28, No. 3

Soroor W. and Popal Z. (2005). Bridging the Gap: Understanding the Mental Health Needs of Afghan Youth. Toronto, Ontario, Canada.

Stewart, F., Barrón, M., Brown, G., Hartwell, M. (2006) Social Exclusion and Conflict: Analysis and Policy Implications. CRISE POLICY PAPER. Oxford: Cen

Tyyskä, Vappu. 2003. Solidarity and Conflict: Teen-Parent Relationships in Iranian Immigrant Families in Toronto, in Lynn Marion, ed. Voice. Essays on Canadian Families, $2^{\text {nd }}$ edition. Toronto: Nelson Canada

Wang, S., Truelove, M. (2003). Evaluation of settlement services programs for newcomers in Ontario: a geographic perspective. Journal of International Migration and Integration. 4 (4): 577-606. 